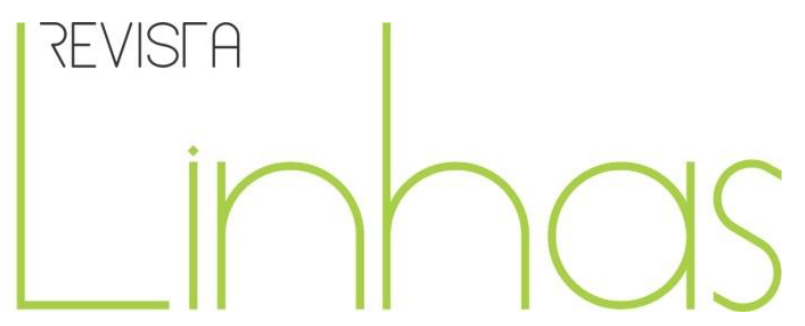

\title{
El Centro Internacional de la Cultura Escolar - del patrimonio y memoria de la educación a la sociedad del conocimiento
}

\begin{abstract}
Resumen
Este trabajo muestra al Centro Internacional de la Cultura Escolar en sus objetivos, estructuras y líneas de acción como un instituto dedicado a investigaciones acerca de la cultura de la escuela en una perspectiva historiográfica, pluridisciplinaria y comparativa. Expone los orígenes del centro en sus relaciones con las tradiciones locales y regionales en que se asienta y con la experiencia académica y profesional de sus promotores, adscritos en su mayor parte a las universidades de Castilla y León, aunque en conexión con investigadores de toda España y de todo el mundo, con especial énfasis a Europa y América Latina. Analiza finalmente los campos de estudio en las tres grandes áreas que atiende el CEINCE: Memoria y Patrimonio de la Educación, Manualística y Cultura Escolar y Sociedad del Conocimiento, mostrando algunas líneas específicas de actuación. La presentación se acompaña de algunas imágenes ilustrativas de los espacios del CEINCE.
\end{abstract}

Palabras clave: CEINCE. Cultura Escolar. Patrimonio de la Educación. Memoria de la Educación. Manualística. Sociedad del Conocimiento.
Agustín Escolano Benito

Universidad de Valladolid -

Centro Internacional de la Cultura

Escolar - CEINCE -

Berlanga del Duero/Soria España

aebo5@telefonica.net

\section{Para citar este artigo:}

BENITO, Agustín Escolano. El Centro Internacional de la Cultura Escolar - del patrimonio y memoria de la educación a la sociedad del conocimiento. Revista Linhas. Florianópolis, v. 19, n. 41, p. 11-33, set./dez. 2018. 


\section{The International Center of School Culture - from the heritage and memory of education to the knowledge society}

\begin{abstract}
This text shows the International Center of School Culture in its objectives, structures and lines of action as an institute dedicated to research about the school's culture in a historiographical, multidisciplinary and comparative perspective. It exposes the origins of the center in its relationships with the local and regional traditions in which it is related and with the academic and professional experience of its promoters, mostly assigned to universities of Castilla y León, although in connection with researchers from all over Spain and around the world, with special emphasis on Europe and Latin America. Finally, it analyzes the fields of study in the three large areas served by CEINCE: Memory and Heritage of Education, School textbooks and School Culture and Society of Knowledge, showing some specific lines of action. The presentation is accompanied by some illustrative images of the spaces of CEINCE.
\end{abstract}

Keywords: CEINCE. School Culture. Heritage of Education. Memory of Education. School Textbooks. Knowledge Society.
O Centro Internacional da Cultura Escolar - do patrimônio e memória da educação à sociedade do conhecimento

\section{Resumo}

Este trabalho mostra o Centro Internacional da Cultura Escolar em relação aos seus objetivos, estruturas e linhas de pesquisa, como um instituto dedicado a investigações sobre a cultura escolar em uma perspectiva historiográfica, interdisciplinar e comparativa. O texto expõe as origens do centro e sua relação com os locais tradicionais e regionais com os quais se vincula e com a experiência acadêmica e profissional dos seus promotores, dos quais vários são vinculados a universidades da região de Castilla y León, além da conexão estabelecida com pesquisadores da Espanha e de várias partes do mundo, principalmente da Europa e da América Latina. Por fim, analisa-se os campos de estudo nas três grandes áreas em que o CEINCE atua: Memória e Patrimônio da Educação, Manuais Escolares, Cultura Escolar e Sociedade do Conhecimento, destacando algumas linhas específicas de ação. $O$ artigo está acompanhado de algumas imagens ilustrativas dos espaços do CEINCE.

Palavras-chave: CEINCE. Cultura Escolar. Patrimônio da Educação. Memória da Educação. Manuais Escolares. Sociedade do Conhecimento. 


\section{El Centro Internacional de la Cultura Escolar}

El Centro Internacional de la Cultura Escolar (CEINCE) es una creación promovida por la Asociación Schola Nostra, que se define como un centro integral de documentación, investigación e interpretación en todos los aspectos relativos a la cultura de la escuela, considerada esta en todos sus niveles y modalidades, y en una perspectiva multidisciplinaria e internacional.

El CEINCE abrió sus puertas a comienzos del año 2006 y cumple ahora su primera década de existencia, si bien sus antecedentes históricos se remontan a varias décadas atrás, cuando los promotores comenzaron a formar las colecciones que ahora lo nutren, y que en sus contenidos más visibles se concretan en los 55.000 ejemplares que integran su biblioteca y los numerosos objetos materiales, iconos y otros testimonios que forman parte de sus exposiciones museográficas y de sus fondos patrimoniales.

Los datos de dirección y comunicación son los siguientes:

CEINCE

c/ Real, 35, y Saúco, 2

42360 BERLANGA DE DUERO, Soria/ESPAÑA

Teléfono: 34.975 .34312

Website: www.ceince.eu

Blogger: BLOGGER CEINCE

El logo del CEINCE, en la Foto 1, a continuación, es un icono que reproduce el laberinto de la casa de Lucrecio en Pompeya. Por el entramado del dédalo circula Teseo (alumno) acosado por Minotauro. En la salida, el hilo de Ariadna (educador/a) ayuda a Teseo a salvar las dificultades que encuentra en el intrincado laberinto de la vida y de la escuela. 

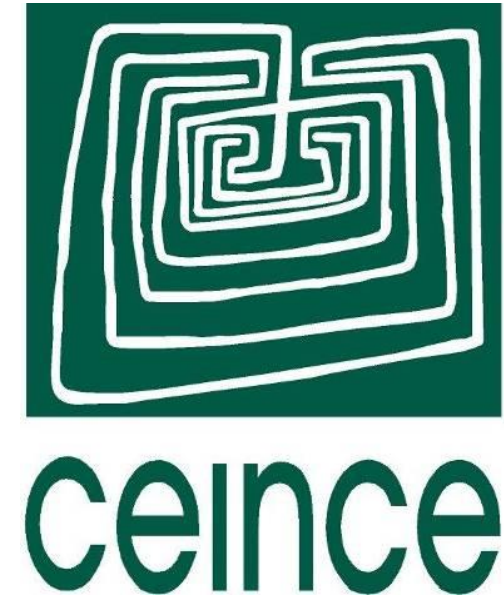

Foto 1 - Logo institucional del CEINCE

Fuente: Archivo CEINCE

La Foto 2, a continuación, enseña el edificio central de la sede del CEINCE. Es un palacio del siglo XVI declarado por Real Decreto de 1980 monumento histórico-artístico nacional de forma individualizada. La casa perteneció a la familia de Juan Bravo, Comunero de Castilla.

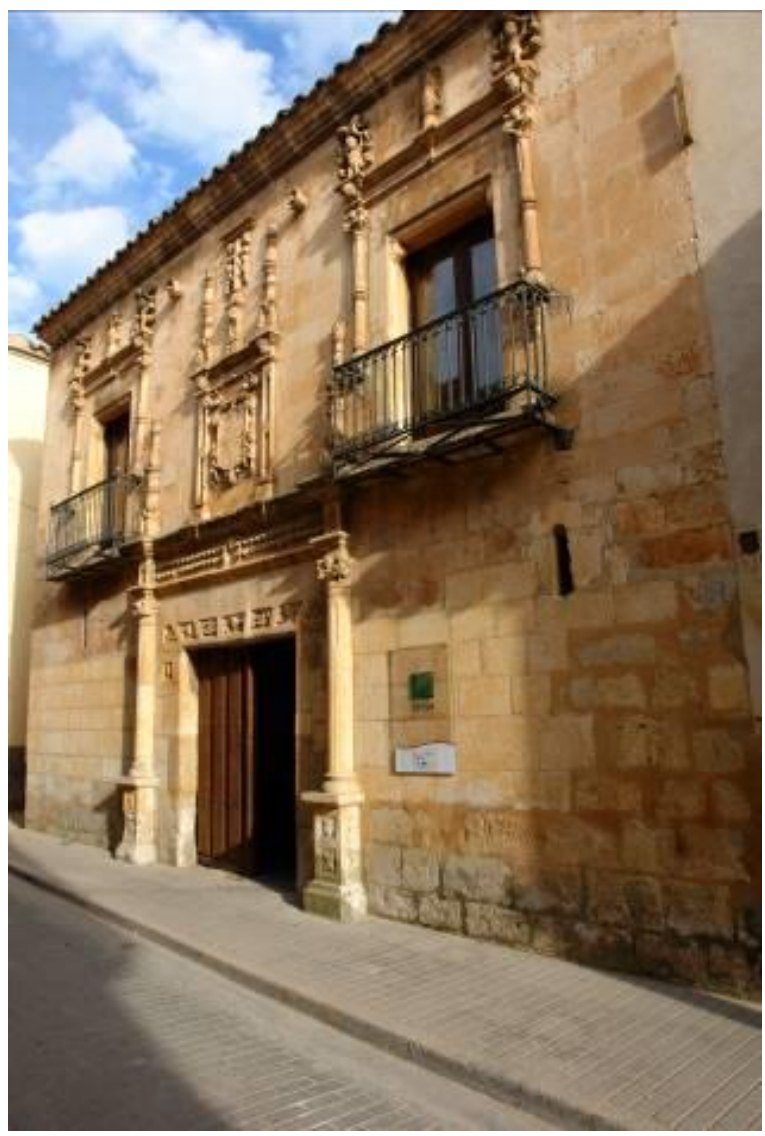

Foto 2 - Edificio del CEINCE

Fuente: Archivo CEINCE 
La Asociación que impulsa el CEINCE está integrada por profesores de las universidades de Valladolid, Burgos y Salamanca, así como por enseñantes de otros niveles educativos vinculados a proyectos de innovación pedagógica y por agentes del sector de la educación no formal. Cuenta además con amplio círculo de amigos y colaboradores que proceden de diversas zonas de Castilla y León y de otras regiones del país, así como con un nutrido y relevante Consejo Académico Nacional e Internacional que juega un papel activo en la programación y orientación de las acciones culturales y pedagógicas del centro.

El CEINCE tiene por objeto específico el estudio integral de la cultura escolar, campo que aborda en toda su extensión y complejidad, bajo una orientación pluridisciplinaria, y en todas las perspectivas de la temporalidad, desde la historiográfica a la prospectiva. La cultura de la escuela se concibe como el conjunto de prácticas (cultura empírica), formaciones discursivas (cultura teórica) y construcciones normativas (cultura política) que informan y regulan la vida de las instituciones educativas y configuran la profesionalidad de los docentes y el comportamiento de todos los actores que intervienen en la educación formal.

A los efectos anteriores, el establecimiento se identifica en primer lugar como un centro de memoria de la educación, y por esto comporta, como dimensión esencial de sus acciones, un programa historiográfico y museológico, cuya finalidad es reconstruir la tradición pedagógica y ponerla en interacción con los procesos formativos y de educación de la ciudadanía. Así se concibió el centro desde el primer proyecto presentado, en 2003, al Programa Leader de la Unión Europea, que apoyó la puesta en marcha de la iniciativa.

El CEINCE se concibe asimismo como un centro de estudios orientado a la interpretación y análisis de las tendencias emergentes que pueden observarse en los sistemas educativos de nuestro tiempo, y de las prolongaciones que estas emiten hacia la sociedad del conocimiento e intercultural.

Las dos dimensiones señaladas aparecen vinculadas en el diseño del nuevo centro. La reconstrucción del patrimonio y la creación de centros de memoria se legitima si se plantea desde las expectativas de futuro de las comunidades que impulsan estos 
proyectos culturales, y no sólo desde supuestos ritualizadores y conservacionistas del pasado. Se recupera la memoria porque el futuro reclama necesariamente la tradición. Sabemos quiénes somos y hacia dónde nos dirigimos porque poseemos memoria. Construimos nuestra cultura escribiendo y borrando, como en los juegos de arena, los recuerdos. En estos juegos salvamos los bienes de nuestro patrimonio, un capital inalienable para la misma identidad. Más allá de la llamada historia anticuaria nos importa el desvelamiento de las huellas impresas en los objetos en que se materializa el patrimonio de la educación y el valor de las señales que exhiben los bienes culturales para orientar la construcción del sentido.

La Foto 3, a continuación, muestra la visita a la exposición estable "Mi Querida Escuela" de un grupo de alumnos de diversas nacionalidades, coincidiendo con la estancia en el CEINCE de la profesora Gladys Teive, de la Universidad de Santa Catarina, Brasil.

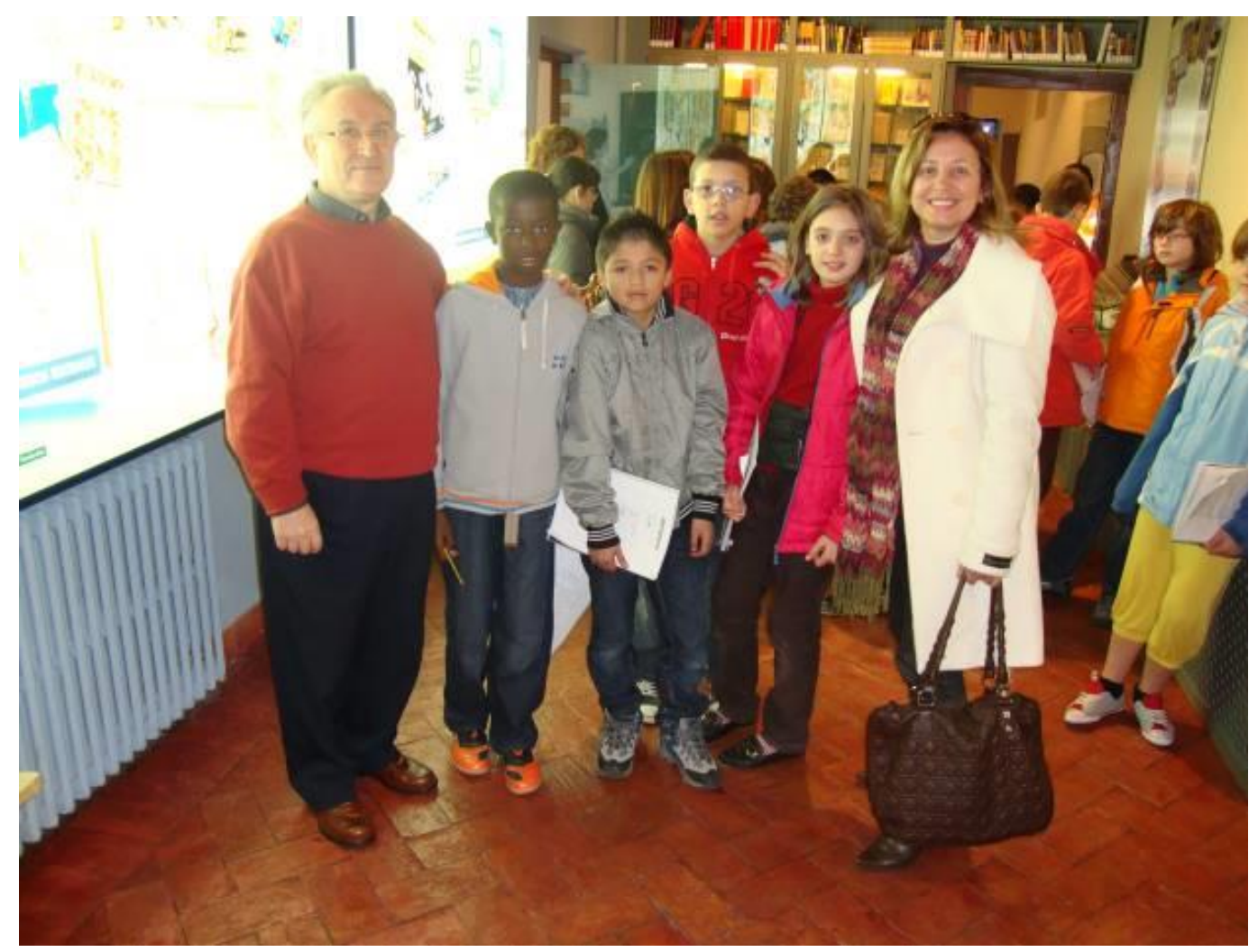

Foto 3 - Grupo de alumnos, en visita a la exposición “Mi querida Escuela” del CEINCE Fuente: Archivo CEINCE 
A continuación, en la Foto 4, se puede ver la imagen correspondiente al acto académico de presentación del CEINCE en el Aula Zamboni de la Universidad de Bolonia, Italia, en octubre del año 2016.

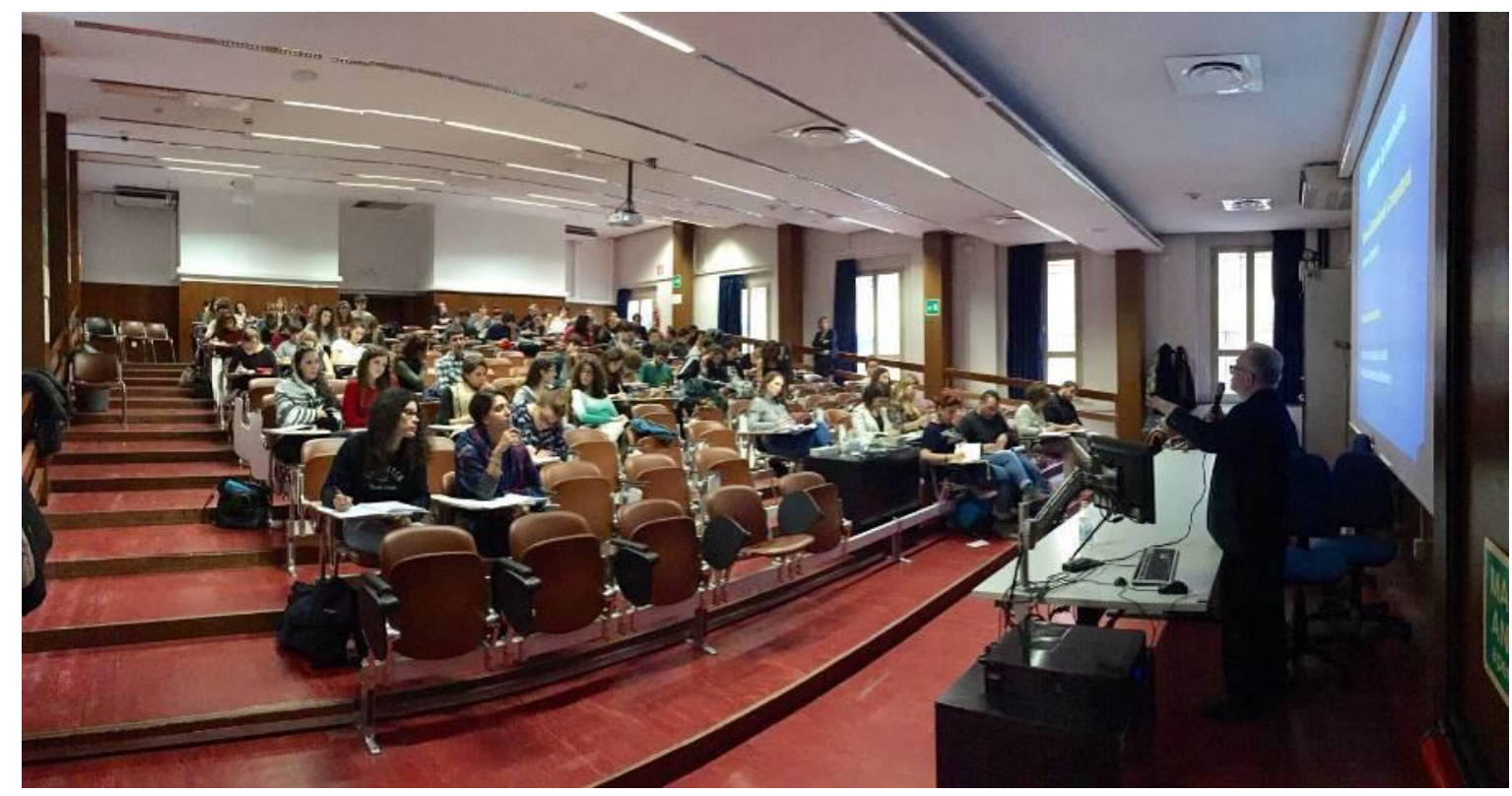

Foto 4 - Acto académico de presentación del CEINCE, en Bolonia/Italia, en 2016.

Fuente: Archivo CEINCE

El futuro de la escuela, respecto al cual el CEINCE se constituye en observatorio y centro de interpretación, se intuye como apertura y creación, pero se escribe o diseña desde el ethos estructurante de la memoria. Precisamente por ello, el patrimonio material e intangible de la escuela, que es un valor público, ha de ser preservado, investigado y difundido. $Y$ justamente por ello el CEINCE se perfila como centro de innovación y de investigación histórica, esto es, como un instituto de análisis e interpretación de expectativas y como un centro de memoria de la educación en sus relaciones con los atributos de la cultura y las realidades de nuestro tiempo.

\section{Antecedentes: la tradición del lugar}

La Asociación Schola Nostra, que se constituyó en el año 2003, y el CEINCE, que nace en 2006, se asientan sobre uno de los segmentos del patrimonio más significativos 
de la Comunidad de Castilla y León, el educativo. Los orígenes del proyecto se pueden analizar en varios tiempos. Por un lado, se han de considerar las prácticas de recuperación de los elementos patrimoniales y de los contenidos bibliográficos y museísticos, cuya génesis se ha de situar a finales de los años sesenta del siglo anterior. Por otra, en una escala de tiempo más próxima, hay que valorar las iniciativas que se pusieron en marcha en el entorno de Berlanga de Duero y en la Universidad de Valladolid desde hace 2/3 décadas.

El proyecto, presentado al Programa Leader en 2003, es percibido por la agencia europea que lo apoya como una iniciativa de alto potencial innovador en cuanto a la preservación de las identidades colectivas y a la instrumentación de esta tradición como memoria activa para impulsar modelos de cambio pensados históricamente y con proyección, en cuyas prácticas se combinan el desarrollo rural-local con los procesos de modernización que asocian los valores culturales y ecológicos o sostenibles con los presupuestos avanzados de la sociedad del conocimiento.

En este orden de cosas, el CEINCE planteó una alternativa para la recuperación del patrimonio material e inmaterial de la educación de la zona en que se radica, para su puesta en valor y para la implementación de programas que impulsen la investigación histórico-pedagógica, la formación y la innovación. Al mismo tiempo, el centro fomenta nuevas formas de uso cultural del ocio en la línea de las modernas acciones que refuerzan las democracias culturales en las sociedades avanzadas por medio del turismo y otras formas de animación.

La provincia de Soria, y en general todas las que integran la Comunidad de Castilla y León, cuenta con una acreditada tradición pedagógica y cultural. Adscrita al llamado “corredor de la escolarización y la alfabetización”, tal como lo registró a comienzos de la última centuria Lorenzo Luzuriaga, este territorio castellano siempre ha ocupado un lugar destacado en los parámetros más representativos de la cultura escolar y de los hábitos de lectura y escritura que las instituciones educativas promueven. Además, las personas de esta tierra atribuyeron desde años un valor identitario, social y personal, a la educación. En las narrativas sorianas, la escuela aparece siempre como un ámbito general y básico de sociabilidad. 
La red escolar provincial supuso, desde los primeros desarrollos del sistema educativo liberal del siglo XIX, un lugar destacado dentro del conjunto nacional. De la escuela normal de la capital salieron ilustres maestros que no sólo cubrieron las necesidades de la provincia, sino que prestaron servicio en zonas cercanas y alejadas de su territorio. Luis Bello, periodista que visitó centenares de escuelas en toda España a comienzos del siglo XX, descubrió lo que él llamó el "valle de las escuelas", logro en parte de la acción de mecenazgo con los filántropos, además de la implicación de los municipios. El primer monumento público español a la profesión docente, erigido en 1925, exhibe su porte junto a la vieja Universidad de El Burgo de Osma, erigida en el siglo XVI y clausurada en el XIX.

Berlanga de Duero, una de las sedes del Condestable de Castilla, fue cuna de dos de las treinta y cuatro cartillas de alfabetización del Antiguo Régimen que reunió Víctor Infantes en su búsqueda por bibliotecas y archivos de todo el país. El primer editor de manuales, el maestro, impresor y calígrafo Victoriano Hernando, nació en entornos segovianos próximos a Osma. En fin, todo un conjunto de huellas histórico-educativas avalan la existencia de esta tradición escolar en el medio en que se inscribe la acción del CEINCE, una tradición que el centro se propone recuperar para preservarla, estudiarla y ponerla en valor, como memoria viva al servicio del desarrollo y de la sostenibilidad.

Todo lo anterior quiere también poner de relieve que el Proyecto CEINCE va más allá de los horizontes académicos que los profesionales de la historia de la escuela han de atender dentro de la lógica gremial de sus programas académicos, en virtud de que su acción se ordena a cubrir objetivos más generales y desinteresados que tienen que ver con el desarrollo de la comunidad, a cuyo fin se ordena esta política activa de cuidado de un específico y relevante sector de nuestro patrimonio cultural.

El Centro Internacional de la Cultura Escolar se concibió pues, además de cómo iniciativa pedagógica, como núcleo dinamizador del desarrollo de la zona en que está enclavado a través de la implementación de programas socioeducativos relacionados con las tradiciones y posibles expectativas del entorno en las que se pueden sustentar estrategias de sostenibilidad innovadoras que conecten lo local con lo global a través del uso de las nuevas tecnologías y el turismo intercultural. 
EI CEINCE se inserta en un medio natural que aún conserva eslabones importantes para un desarrollo respetuoso con las reglas de una buena gestión del territorio. Por otro lado, como hemos mostrado anteriormente, el proyecto que lo inspira trata de recuperar y poner en valor la memoria activa del lugar, fundamentalmente la vinculada a la experiencia histórica de la escuela y de la educación, una memoria que aún sobrevive en los espacios y entre las personas que los fomentan, que incluso es estimada como un referente clave de identidad antropológica y comunitaria.

La provincia de Soria, un lugar que apenas supera los nueve habitantes por kilómetro cuadrado (Tierras de Berlanga solo tres), se venía postulando desde hace ya algunos años como posible sede territorial del organismo mundial de las Naciones Unidas para el desarrollo sostenible.

EI CEINCE arraiga en este contexto de naturaleza y cultura como una muestra de las posibilidades que ofrece el patrimonio cultural, material e intangible, preservado y gestionado desde los criterios de la nueva sociedad del conocimiento, como un instrumento de desarrollo endógeno del entorno y como una mediación ordenada al fomento de los valores ciudadanos que pueden implementar la nueva estrategia.

La Foto 5, a continuación, muestra una imagen de una visita de alumnos y profesores de la Facultad de Educación de la Universidad de Valladolid al CEINCE. Al fondo, aparecen algunos elementos del patrimonio histórico de Berlanga que forman parte del entorno del centro. 


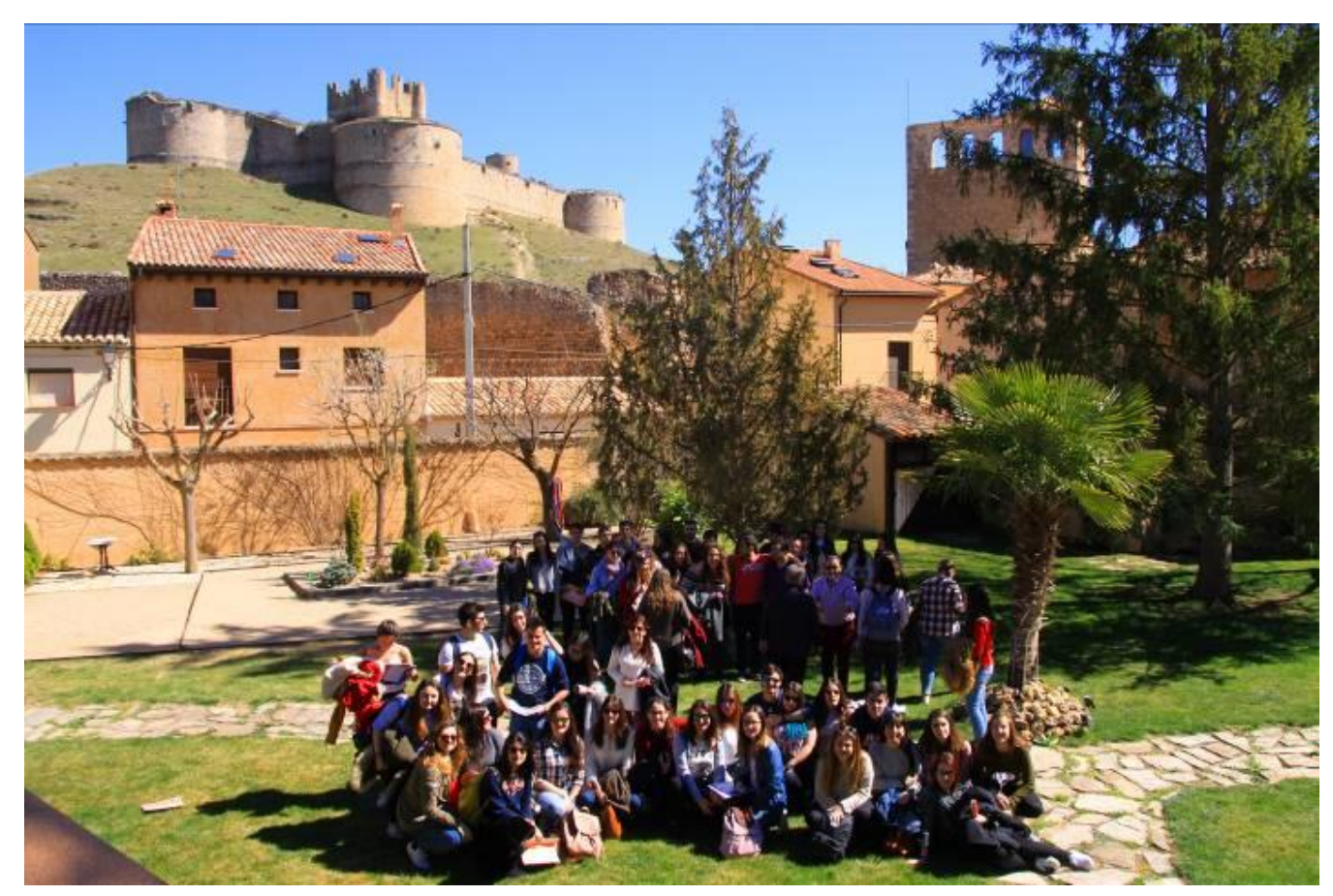

Foto 5 - Visita de alumnos y profesores de la Universidad de Valladolid al CEINCE Fuente: Archivo CEINCE

La imagen de la Foto 6 muestra la biblioteca del CEINCE, con el contenedor en el que se guarda el fondo antiguo del centro, en su mayor parte ya catalogado y dispuesto en nuestra web. La biblioteca acoge más de cincuenta mil volúmenes.

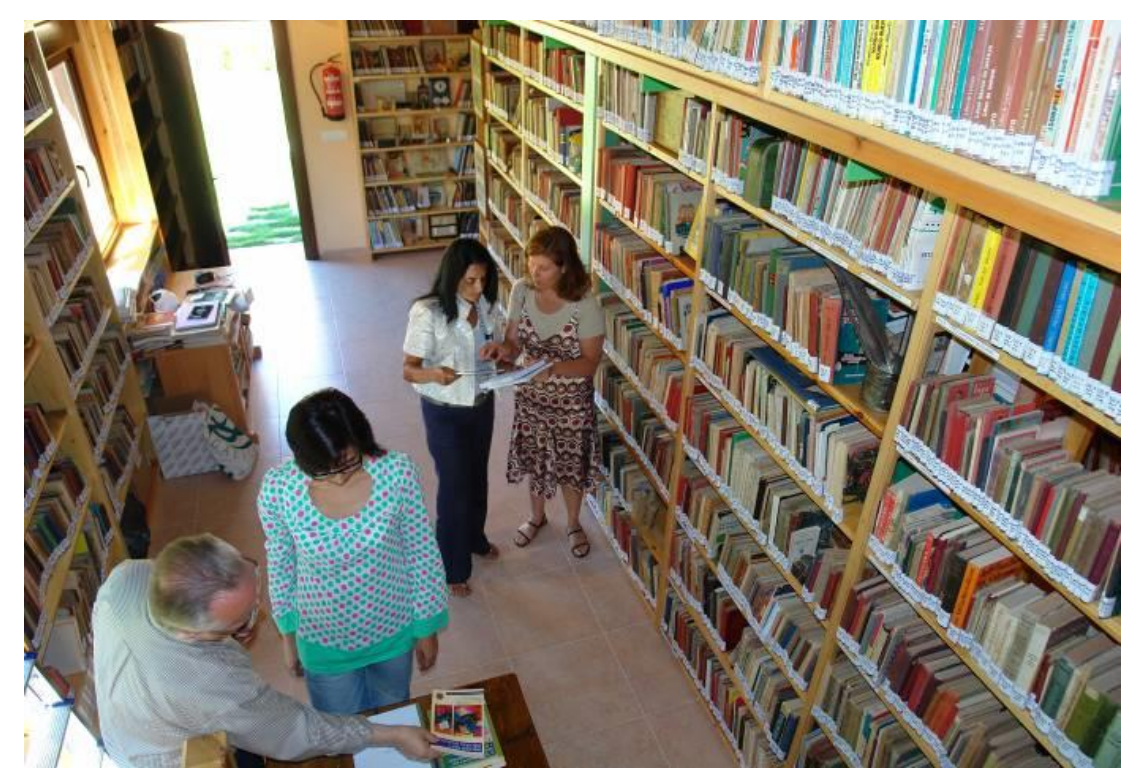

Foto 6 - Imagen de la biblioteca del CEINCE Fuente: Archivo CEINCE 
En los años de despegue del proyecto participamos, desde la Universidad de Valladolid y desde el mismo CEINCE, en colaboración con varios países europeos (Alemania, Francia, Portugal y España) y latinoamericanos (Brasil, Argentina y Costa Rica), en un programa Alfa Europa-América Latina de investigación cooperativa sobre el tema, liderado por la Universidad de Campinas, Brasil, que cerró su primera etapa en octubre de 2007 precisamente en nuestra sede, en Berlanga. El proyecto dio origen a dos publicaciones colectivas que recogen los trabajos más significativos del grupo: Educación superior y desarrollo sostenible (Madrid, Biblioteca Nueva, 2006) y Cambio educativo y cultura de la sostenibilidad (Valencia, Tirant lo Blanch, 2007). Complementariamente a lo anterior, el grupo de investigadores de la Universidad de Valladolid gestionó también un proyecto de investigación, auspiciado por la Junta de Castilla y León, acerca de las relaciones entre educación, conocimiento y sostenibilidad.

Los anteriores estudios eran al tiempo un buen ejemplo de la armonización de las instancias prácticas del desarrollo y las que afectan a los supuestos históricos y epistémicos de los modelos sostenibles. En su dimensión historiográfica, que se asocia a planteos como los derivados del protoecologismo de Rousseau y de los krausistas españoles del siglo XIX, se ilustraba la tesis de que los discursos y las prácticas a favor de una nueva relación hombre-naturaleza tienen ya una importante tradición y no son modas diletantes de la posmodernidad. Igualmente se mostraba cómo los modelos teóricos del llamado por Edgar Morin pensamiento ecologizante tenían un importante potencial sistémico y hermenéutico para la comprensión de las estrategias de sostenibilidad y sus resultados efectuales en el mundo actual.

Desde la perspectiva de la práctica educativa, las primeras investigaciones del CEINCE pusieron de manifiesto que el nuevo paradigma de la sostenibilidad provocaba un giro estructural en toda la cultura de la escuela, en los escenarios en que se desenvolvía la formación, en los tiempos y ritmos que regulaban los procesos de enseñanza, en el habitus de los profesores, en los comportamientos de los alumnos, en los contenidos de la curricula y en los modos de gestionar la ecología de las aulas. EI CEINCE se constituyó, a este respecto, en un observatorio de estos cambios y de las propuestas que se formulaban para afrontar la innovación con racionalidad en contextos reales diversos y 
complejos. Todos estos planteos se gestaron en realidad en el programa de doctorado y grupos de trabajo puestos en marcha en la Universidad de Valladolid, en el marco del Programa PROPIO, que versó sobre los siguientes ejes: Modernidad-TransversalidadSostenibilidad. El origen de estos programas se puede enmarcar entre los años 1993 y 2003, que cubren el ciclo del Programa PROPIO, y su desarrollo se continuó con la puesta en marcha del CEINCE.

\section{Estructura del Centro}

El CEINCE se estructura, desde el punto de vista organizativo, en tres áreas principales:

\subsection{Cultura Escolar y Sociedad del Conocimiento}

Esta área se perfila como un observatorio para la interpretación de la cultura de la escuela en la sociedad contemporánea y para su prospectiva. La cultura de la escuela se debate hoy, desde un uso inteligente de la memoria, entre los grandes desafíos que le suscitan el tiempo presente y las antenas que este proyecta hacia el futuro:

- La entrada en la sociedad del conocimiento.

- El impacto del giro digital y las tecnologías.

- El reto de la diversidad y el interculturalismo.

- Las dimensiones de la globalización.

- Las nuevas relaciones de género.

- El juego democrático entre libertad y equidad.

- La respuesta al paradigma de la sostenibilidad.

Estas son, entre otras, las líneas básicas de investigación que orientan las acciones prioritarias que se desarrollan en el centro. 


\subsection{Memoria de la Escuela y Patrimonio Educativo}

EI CEINCE cubre en este campo todo lo relativo a la recuperación, estudio y puesta en valor del patrimonio material e intangible de la cultura escolar, con especial énfasis en la reconstrucción de la memoria histórica de la educación en el ámbito de la comunidad en que se inserta, pero en una perspectiva de historia comparada intra e internacional. Sus programas prestan atención al archivo, análisis y difusión de las voces y escrituras, los textos, las imágenes y los objetos que constituyen el legado de la tradición y los materiales del ajuar etnográfico de la escuela, es decir, a la arqueo-genealogía cultural de la educación, con la mira puesta en la comprensión de los códigos de la gramática de la escolarización y del habitus de la profesión docente.

\subsection{Manualística y Documentación Educativa}

Esta área cubre el ámbito de la manualística, un sector de conocimiento y análisis académico, relativamente reciente, que atiende a la constitución del catálogo de los textos escolares, impresos excluidos hasta hace poco tiempo del archivo oficial de la memoria cultural, y reivindicados hoy por todos los historiadores como bienes esenciales para analizar los códigos curriculares y los modelos de sociabilidad que nos han educado. EI CEINCE guarda, al respecto, una de las mejores colecciones de manuales escolares que se conservan en España y se ha constituido en un foro de referencia sobre manualística con proyección en los ámbitos nacional e internacional. Los 55.000 volúmenes de la biblioteca han incorporado un importante segmento internacional, con textos de más de treinta países.

\section{4. Ámbitos de actuación}

EI CEINCE lleva a cabo, entre otras, las siguientes actividades:

- Catalogación y difusión del Fondo Documental de Manuales Escolares depositado en el Servicio de Documentación a través de su propio catálogo, al que se tiene acceso a través de la web del centro y de la web de la Fundación Germán Sánchez Ruipérez, 
entidad de mecenazgo dedicada al fomento de todos los aspectos relativos a la cultura del libro que apoyó de forma decisiva el funcionamiento del CEINCE durante varios años. En estos momentos está catalogado y en red, gran parte del fondo antiguo.

- Incorporación del Fondo Documental del CEINCE a la Base Manes coordinada por el Centro de Investigación sobre Manuales Escolares de la Universidad Nacional de Educación a Distancia-Madrid (UNED). La UNED -con la que el CEINCE tiene firmado convenio-- coordina desde hace ya quince años el proyecto MANES, en el que participan más de veinte universidades españolas y latinoamericanas.

- Asesoramiento en consultas in situ y a distancia sobre los campos temáticos y documentales que cubre el Centro. En los diez años de funcionamiento, el CEINCE ha sido visitado por profesores e investigadores de las 17 Comunidades Autónomas de España y 52 países del mundo, de todos los continentes, aunque especialmente por países de Europa y América. Estos indicadores dan idea del nivel de internacionalización que ha logrado el centro.

- Formación y tutoría de doctorandos, investigadores, becarios y profesionales en distintos campos de la cultura de la escuela. En la actualidad se han atendido un total de 321 estancias de investigación. Los datos de estas estancias, incluidas las temáticas y el origen de los investigadores, se pueden consultar en la web del CEINCE (ActividadesHistorial-Memorias-Papeles del CEINCE). El flujo cotidiano de estas visitas se puede seguir en BLOGGER CEINCE.

- Diseño, montaje y difusión de exposiciones temáticas sobre distintos aspectos de la cultura escolar. Como muestra estable, el CEINCE ofrece una retrospectiva de los dos últimos siglos de la historia de la escuela en España (Exposición “Mi Querida Escuela”). El centro ofrece asimismo exposiciones monográficas, algunas de las cuales son itinerantes (“Cómo aprendimos a leer”, “La España cubista”, “Escrituras infantiles”...).

- Desarrollo del programa Archivo de la Memoria de la Educación con captación, registro y explotación de fuentes orales, escritas, icónicas y materiales producidas por los actores de la escuela. Este programa se vincula a enfoques etnohistóricos y 
antropológicos bajo una perspectiva asociada a la nueva historia cultural y material de la escuela.

- Organización de cursos, seminarios, coloquios y otras reuniones científicas y pedagógicas regionales, nacionales e internacionales en torno a cuestiones relevantes de las áreas en que se estructura la cultura de la escuela como campo intelectual y académico. Hasta ahora se han desarrollado un total de 76 eventos de diversos formatos.

- $\quad$ Proyecto de museización de un Itinerario Histórico Escolar sobre la escuela rural de Castilla y León en el siglo XX. Este proyecto incluye la rehabilitación y puesta en valor de escuelas cerradas en el entorno cercano a Berlanga de Duero (en un radio de unos 15 kms) correspondientes a distintos ciclos históricos, con la intencionalidad de posibilitar la visita a todas ellas en una jornada de turismo cultural.

La Foto 7, a continuación, muestra un registro de la ocasión de uno de los Coloquios Internacionales. El encuentro es una Sesión de trabajo del Coloquio hispanobrasileño sobre cultura material de la escuela, celebrado en 2016 , con presencia de colegas de las universidades de Santa Catarina, Campinas, Paraná, Valladolid y Burgos.

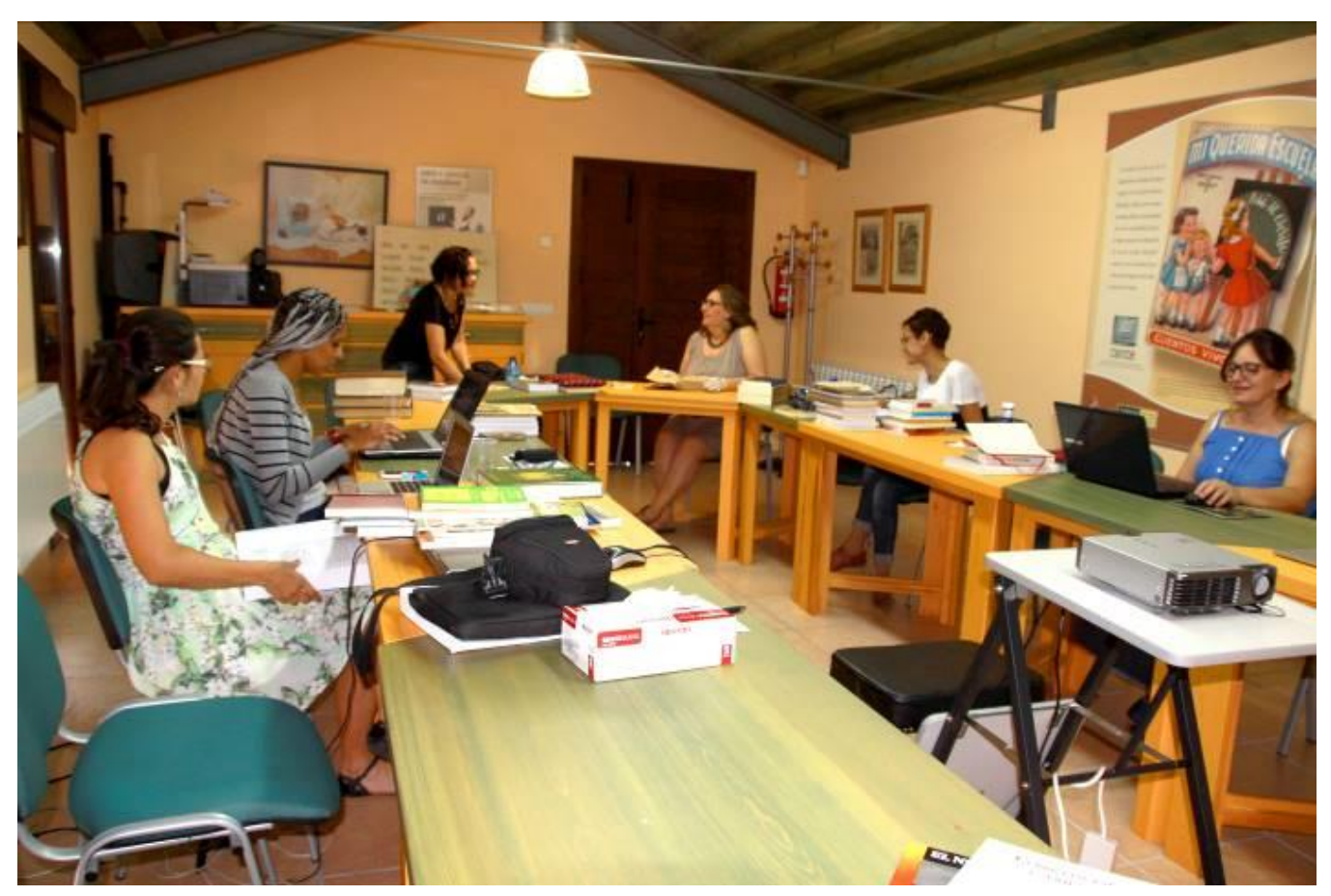

Foto 7 - Coloquio hispano-brasileño sobre cultura material de la escuela, 2016 Fuente: Archivo CEINCE 
A continuación, la Foto 8 , de otro evento, muestra un registro de una Sesión de trabajo del Coloquio Europeo History online Project, celebrado en 2008, con la participación de profesores de diversas universidades de Italia, Francia, España, Portugal, Turquía y Alemania.

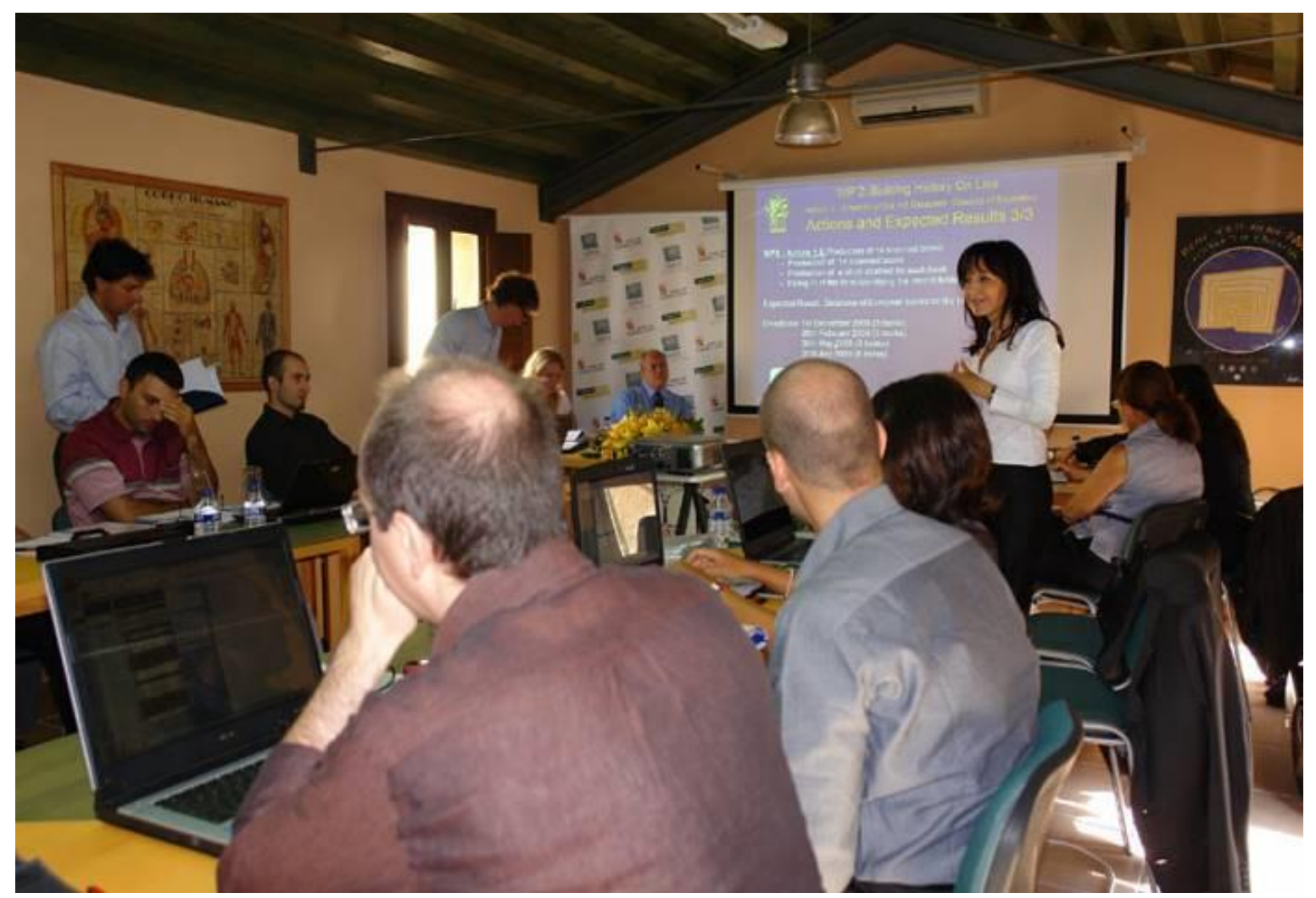

Foto 8 - Coloquio Europeo History online Project, 2008 Fuente: Archivo CEINCE

- Coordinación y dinamización de la RIHE, Red Internacional de Hermenéutica Educativa, organización constituida en el CEINCE en 2007 con grupos de trabajo de universidades de España, Italia y México que ha dado origen a diversos eventos en los tres países y a diversas publicaciones.

- Gestión y animación de programas específicos, entre los que se destacan tres: Etnografía de la Escuela en Castilla y León, Innova Escuela, Usos Terapéuticos del Patrimonio (Asociación Alzheimer de Soria). 
- Dinamización cultural en contextos de educación no formal con diversos colectivos infantiles, juveniles, adultos y seniors. Acciones de educación popular.

\section{El CEINCE en cifras, 2006-2016}

Datos (visitantes-cursos-estancias-convenios)

- Visitantes a exposiciones: 12.476

- Profesores e investigadores. Cursos: 2.493

- Cursos y coloquios: 84

- Estancias individuales e investigación: 321

- Convenios con entidades e instituciones: 23

Procedencia (nacional)

- Localidades provincia de Soria: 109

- Castilla y León (provincias): 9

- CC Autónomas: 17

Procedencia (internacional)

- Países: 53

Alemania, Argentina, Australia, Bélgica, Bielorrusia, Brasil, Bolivia, Bulgaria, Cabo Verde, Camerún, Canadá, Colombia, Costa Rica, Cuba, Chile, China, Dinamarca, Ecuador, El Salvador, Estados Unidos, Finlandia, Francia, Grecia, Guatemala, Guinea, Holanda, Honduras, India, Italia, Irán, Irlanda, Israel, Japón, Marruecos, México, Nicaragua, Noruega, Panamá, Perú, Polonia, Portugal, Puerto Rico, Reino Unido, República Dominicana, Ruanda, Rumania, Rusia, Suecia, Suiza, Turquía, Uruguay, Venezuela, Zimbabwe.

Universidades (nacional e internacional)

- Universidades y centros superiores: 159

- España: 43 


\section{- Europa: 51}

- América: 56

- Otros: 9

Biblioteca: Alrededor de 55.000 volúmenes

La Foto 9, a continuación, muestra una imagen de la sala $4^{\text {a }}$ de la Exposición "Mi Querida Escuela”, denominada “escuela.net". La escena refleja el impacto en la escuela de la sociedad intercultural y las nuevas tecnologías.

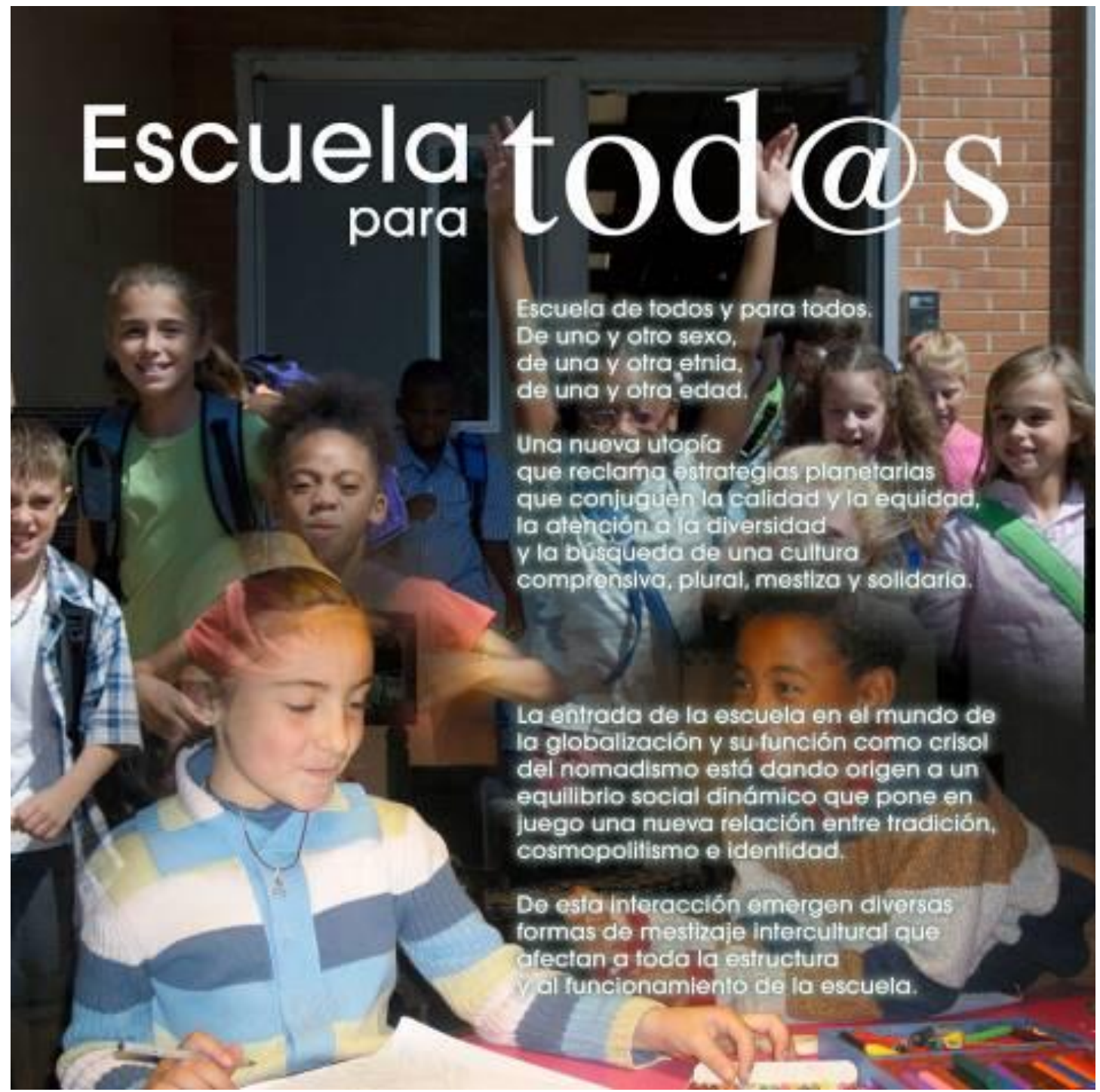

Foto 9 - Sala 4 a de la Exposición "Mi Querida Escuela" - "escuela.net" Fuente: Archivo CEINCE 
En la próxima imagen, en la Foto 10, hay una escena tomada en una sesión de usos terapéuticos del patrimonio histórico educativo con enfermos de Alzheimer que tratan de identificar recuerdos escolares.

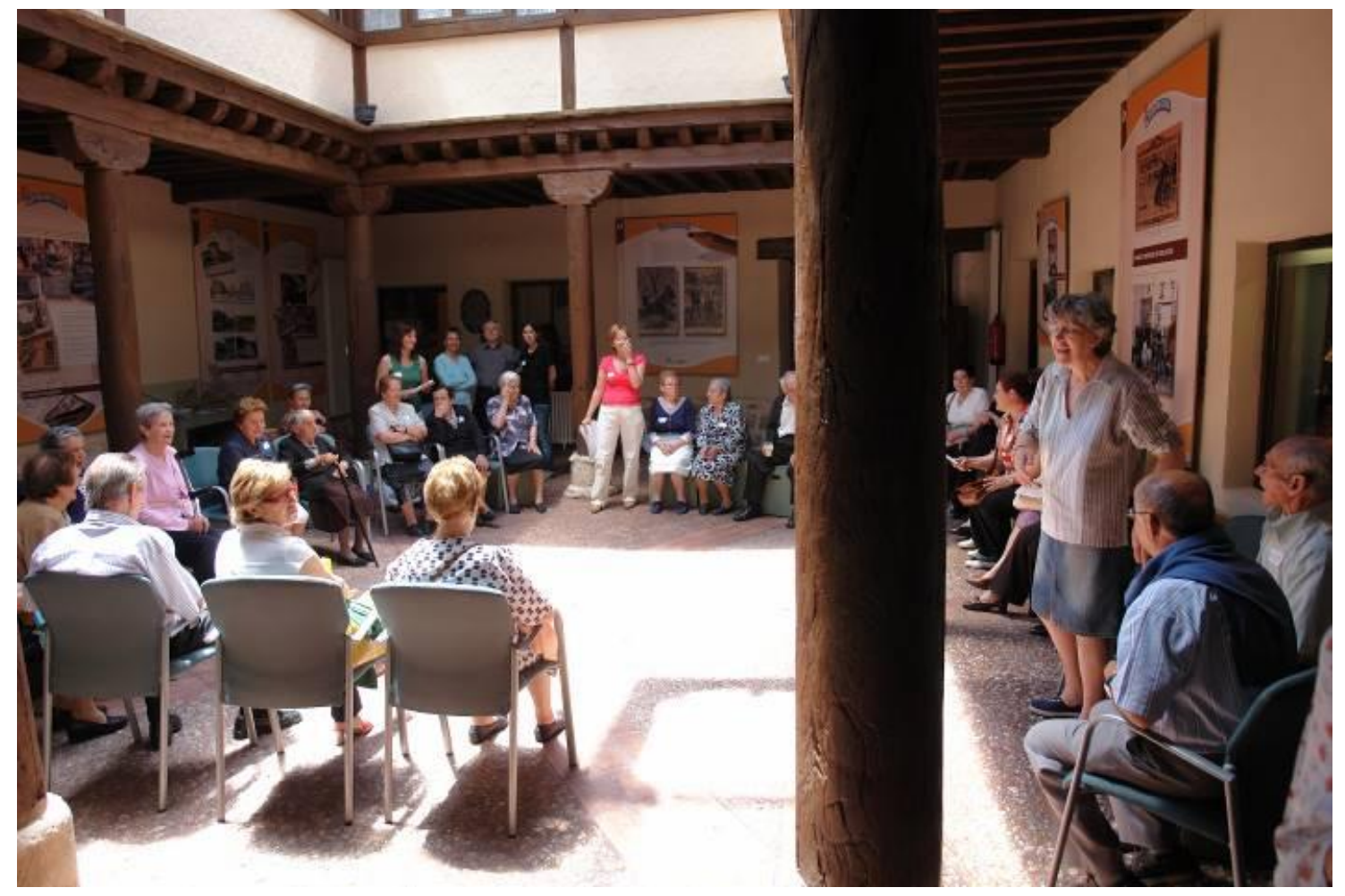

Foto 10 - Sesión de usos terapéuticos del patrimonio histórico educativo con enfermos de Alzheimer Fuente: Archivo CEINCE

\section{Conclusión y perspectiva}

A lo largo de la primera década de su funcionamiento efectivo, el CEINCE se ha configurado como un instituto superior de educación orientado al estudio, análisis y debate del patrimonio histórico-educativo y la cultura de la escuela, en el que se conjuga la investigación acerca de la memoria recuperada y el examen crítico de las cuestiones más candentes de la educación en la sociedad del conocimiento. En el CEINCE participan profesores e investigadores de todos los niveles educativos y de muy diversas procedencias geográficas, profesionales y culturales, lo que permite el análisis transversal 
e internivelar del universo de la educación y el estudio comparado de las cuestiones que son objeto de análisis.

El CEINCE, en sólo una década, aunque con antecedentes importantes, ha llegado a acumular un rico y variado repertorio de textos, imágenes, objetos y otros testimonios que configuran un rico muestrario del patrimonio histórico-educativo. Este patrimonio se está difundiendo entre amplias capas de la población, como bien de interés público que es, contribuyendo así a dar visibilidad a la escuela como cultura y a la democracia ilustrada de la ciudadanía que se ha educado entre sus muros.

La acción del CEINCE ha logrado asimismo influir en su entorno cercano como agencia de desarrollo y, en perspectiva globalizada, en todos los medios regionales, nacionales e internacionales que han participado en unas $u$ otras experiencias desarrolladas en su sede y en el exterior, promoviendo el análisis comparado de las acciones y el sentimiento de pertenencia a una sociedad educada que debe mucho a la escuela como institución cultural.

Cumplir una década intensa de trabajos invita a la reflexión. En ello estamos, con la expectativa de poder prolongar y potenciar la experiencia acumulada y de asegurar la transmisión de este importante legado a la siguiente generación. La escuela ha sido desde hace dos siglos una agencia esencial en la sociabilidad cultural de los sujetos y en la construcción de imaginarios colectivos. La escuela para todos - cualquiera sea la forma institucional o modal que adopte - seguirá siendo una mediación que definirá nuestra subjetividad y nuestra cultura. 


\section{Referencias}

AYUSO, María Luz. Entrevista con Agustín Escolano Benito - Cultura material de la escuela y Educación Patrimonial: una mirada desde el Centro Internacional de Cultura Escolar. Propuesta Educativa, FLACSO Argentina, n. 34, año 19, v. 2, nov. 2010, p. 77-85.

BASTOS, Maria Helena Camara. A pesquisa em História da Educação - testemunho de um autor: entrevista com Agustín Escolano. História da Educação, v. 20, n. 50, set./dez. 2016.

ESCOLANO BENITO, Agustín (Ed.). La cultura material de la escuela. Berlanga/Soria: CEINCE, 2007.

ESCOLANO BENITO, Agustín. A escola como cultura: experiência, memória e arqueologia. Traducción de Heloisa Pimenta y Vera Lucia Gaspar, prólogo de Diana G. Vidal y nota de Antonio Nóvoa. Campinas: Alínea, 2017.

ESCOLANO BENITO, Agustín. EI CEINCE como centro de memoria e interpretación de la cultura de la escuela. Participación Educativa, Ministerio de Educación - Consejo Escolar del Estado, 9, 2008, p. 131-141.

ESCOLANO BENITO, Agustín. Patrimonio material de la escuela e historia cultural. Linhas, Universidad de Santa Catarina, Brasil, v. 11, n. 2, 2010, p. 13-28.

ESCOLANO BENITO, Agustín. Sherlock Holmes goes to school. Etnohistory of the school and educational heritage. History of Education \& Children's Literature, Macerata-Italia, v. 2, 2010, p. 17-32.

ESCOLANO BENITO, Agustín. Spain. The CEINCE. China Children's Culture, Zheijang, 2009.

ESCOLANO BENITO, Agustín. Spain: The International Centre of School Culture.

Ricercazione, Trento, 3-2, 2011, p. 289-296.

ESCOLANO BENITO, Agustín. The International Centre for School Culture as e Centre of Memory and Interpretation. History of Education \& Children's Literature, III, MacerataItalia, 2008, p. 473-487.

ESCOLANO BENITO, Agustín. The manual as text. The construction of an identity. In: VAN GORP, A. \& DEPAEPE, M. (Eds.). Auf der Suche nach der wahren Art von Textbüchern. Bad Heilbrunn: Klinkhardt, 2009, p. 37-49.

ESCOLANO BENITO, Agustín; BRYAN, Newton Antonio Paciulli; SUAREZ, Henar Herrero. Educação e conhecimento para um futuro sustentável. Campinas: Alínea, 2011.

LAWN, Martin (Ed.). Modelling the Future. Exhibitions and the Materiality of Education. Oxford: Symposium Books-CEINCE, 2009. 
TEIVE, Gladys Mary Ghizoni; ÁLVAREZ, María de los Ángeles Rodríguez. Memoria plasmada en el presente: conversaciones con Agustín Escolano Benito. Revista Brasileira de História da Educação, v. 13, n. 3 (33), set./dez. 2013, p. 15-28.

Recebido em: $08 / 04 / 2018$ Aprovado em: 10/06/2018

Universidade do Estado de Santa Catarina - UDESC Programa de Pós-Graduação em Educação - PPGE Revista Linhas Volume 19 - Número 41 - Ano 2018 revistalinhas@gmail.com 